\title{
Bovine response to lipoarabinomannan vaccination and challenge with Mycobacterium paratuberculosis
}

\author{
Ana Jolly ${ }^{1}$, Claudia Morsella ${ }^{2}$, Laura Bass ${ }^{1}$, María Andrea Fiorentino ${ }^{2}$, \\ Fernando Alberto Paolicchi ${ }^{2}$, Silvia Leonor Mundo ${ }^{1}$ \\ ${ }^{1}$ Cátedra de Inmunología, Facultad de Ciencias Veterinarias, Universidad de Buenos Aires, \\ Buenos Aires, Argentina. \\ ${ }^{2}$ Laboratorio de Bacteriología, Estación Experimental Agropecuaria Balcarce, \\ Instituto Nacional de Tecnología Agropecuaria, Balcarce, Argentina.
}

Submitted: August 16, 2012; Approved: November 13, 2012.

\begin{abstract}
This study aimed to evaluate the immune response in bovines following immunization with a mycobaterial Lipoarabinomannan extract (LAMe) and the effect of Map challenge. LAMe vaccine induced specific antibody levels that diminished after the challenge and affected Map excretion at least for 100 days thereafter.
\end{abstract}

Key words: paratuberculosis; bovine; LAM; humoral immune response; experimental challenge.

Paratuberculosis is a chronic enteritis affecting ruminants, caused by Mycobacterium avium subsp. paratuberculosis (Map). Current commercial vaccines, based on live or killed Map strains, feature both antibodyand cell-mediated immunity, and can cause a significant reduction in bacterial shedding conferring a partial protection against paratuberculosis (Bastida and Juste, 2011). These vaccines induce reactivity to mycobacterial antigens such as purified protein derivative (PPD) and protoplasmic antigen (PPA), which are widely used to identify infected cattle (Nielsen 2010). In countries where bovine tuberculosis is endemic, such as Argentina, vaccination against paratuberculosis is hampered by the interference with the intradermal tuberculin test.

Lipoarabinomannan (LAM) is the most immunogenic glycolipid antigen and a key virulence factor on the mycobacterial envelope (Nigou et al., 2003; Welin et al., 2008). Antibodies against LAM have been shown to be beneficial in passive protection experiments in tuberculosis models (Glatman-Freedman, 2006). The role of the humoral immune response on infection and protection in paratuberculosis remains controversial. We have previously shown that specific antibodies (against LAM or other Map antigens) could have beneficial effects in macrophage infection assays (Jolly et al., 2011; Mundo et al., 2008).
This study aimed to evaluate the kinetics of the humoral immune response in bovines following immunization with a mycobacterial LAM-enriched glycolipid extract (LAMe) and the effect of Map challenge.

Ten six-month-old Aberdeen Angus (Bos taurus) calves from tuberculosis-free accredited and paratuberculosis-free herds were kept in an experimental field from INTA Balcarce (Argentina) and were randomly assigned to these treatment groups: LAMe vaccinated group (LAMv, $\mathrm{n}=5$ ), Ma vaccinated group (Mav, $\mathrm{n}=3$ ) and FIA control group $(\mathrm{C}, \mathrm{n}=2)$, which were inoculated subcutaneously on days 0, 40, 90 and 170 with LAMe, Mycobacterium avium subsp. avium (Ma) or PBS, respectively, prepared as previously described (Jolly et al., 2006, 2011). The experiment was approved by the "Institutional Committee for the Care and Use of Animals for Experimental Procedures" from INTA. The Map inoculum was produced by conventional culturing (Stabel, 1997) of a local strain, first isolated from feces of a dairy cow with clinical signs of paratuberculosis and positive result in PPA-ELISA, obtained from the Laboratory of Bacteriology (INTA Balcarce), and identified as "A" pattern (European type RC17) by IS900-PCR and Restriction Fragment Length Polymorphism (RFLP) (Moreira et al., 1999). 
Ten days after the last immunization (day 180 of the experiment), two bovines from the LAMv group, randomly selected, and the two from the $\mathrm{C}$ group were challenged by intraruminal inoculation for two consecutive days with a total dose of $200 \mathrm{mg}$ wet weight of bacterial pellet (Hines et al., 2007). Viable bacteria were retrospectively determined by serial plating onto Herrolds medium, resulting in a total inoculum of $1 \times 10^{9} \mathrm{cfu}$ for each animal.

Serum ELISA reactivity to LAMe, Map and PPA was assessed on days $0,40,90,180$ and 280 , following previously described methodology (Fernández et al., 2012; Jolly et al., 2011). All immunized calves developed specific antibodies against LAMe and Map after vaccination (Figure $1 \mathrm{~A}$ and $\mathrm{B}$ ), whereas the control group did not show positive results (Figure 1C). A single dose of LAMe vaccine induced the highest level of specific antibodies detected, independently of the antigen evaluated (LAMe or Map). The second dose of LAMe did not increase these levels (Figure 1A). These findings seem to be consistent with the glycolipid nature of this antigen and the way in which this kind of antigens stimulate an immune response (Abbas and Lichtman, 2004). In the case of the Mav group, we found a different kinetics of the humoral immune response against the evaluated antigens. Animals in this group required at least two doses to stimulate the production of high levels of specific antibodies (Figure 1B). This apparent delay in the antibody peak after vaccination has been already described by other authors for Map proteic antigens (Muskens et al., 2002; Stabel et al., 2011). The differences in reactivity against LAMe detected between the LAMv and the Mav groups could be related to the thermolability of LAM during heat inactivation of bacteria (Kang et al., 2005) or to the influence of protein compounds present in the whole bacterial vaccine. Both experimental vaccines (LAMe and $\mathrm{Ma}$ ) induced PPA reactivity with the first dose. Nevertheless the LAMv group maintained low reactivity levels with successive doses, whereas the Mav group continued increasing them until the final time point. This temporary reactivity detected against PPA in the LAMv group could be related to the presence of protein traces in LAMe or of small amounts of LAM in PPA.

IFN $\gamma$ production of whole blood cells stimulated with PPDa and PPDb was assessed on days 0, 90 and 180 (prior to challenge) (Paolicchi et al., 2003) using the Duoset Elisa Development Kit (R\&D Systems Inc., MI, USA). Basal levels of IFN $\gamma$ were detected in the three groups on days 0 and 90 (values lower than $230 \mathrm{pg} / \mathrm{mL}$ for PPDa and than $200 \mathrm{pg} / \mathrm{mL}$ for PPDb estimulated cells). On day 180, we could detect a significant increase in IFN $\gamma$ levels produced in Mav group when whole blood cells were stimulated with both PPDa $(838 \pm 167 \mathrm{pg} / \mathrm{mL})$ and PPDb $(481 \pm 80 \mathrm{pg} / \mathrm{mL})$, as compared with the levels detected in the other groups, that remained basal $(\mathrm{p}<0.05$, ANOVA and Tukey's test). Immunization with LAMe did not induce the specific secretion of this cytokine in any of the evaluated time points,
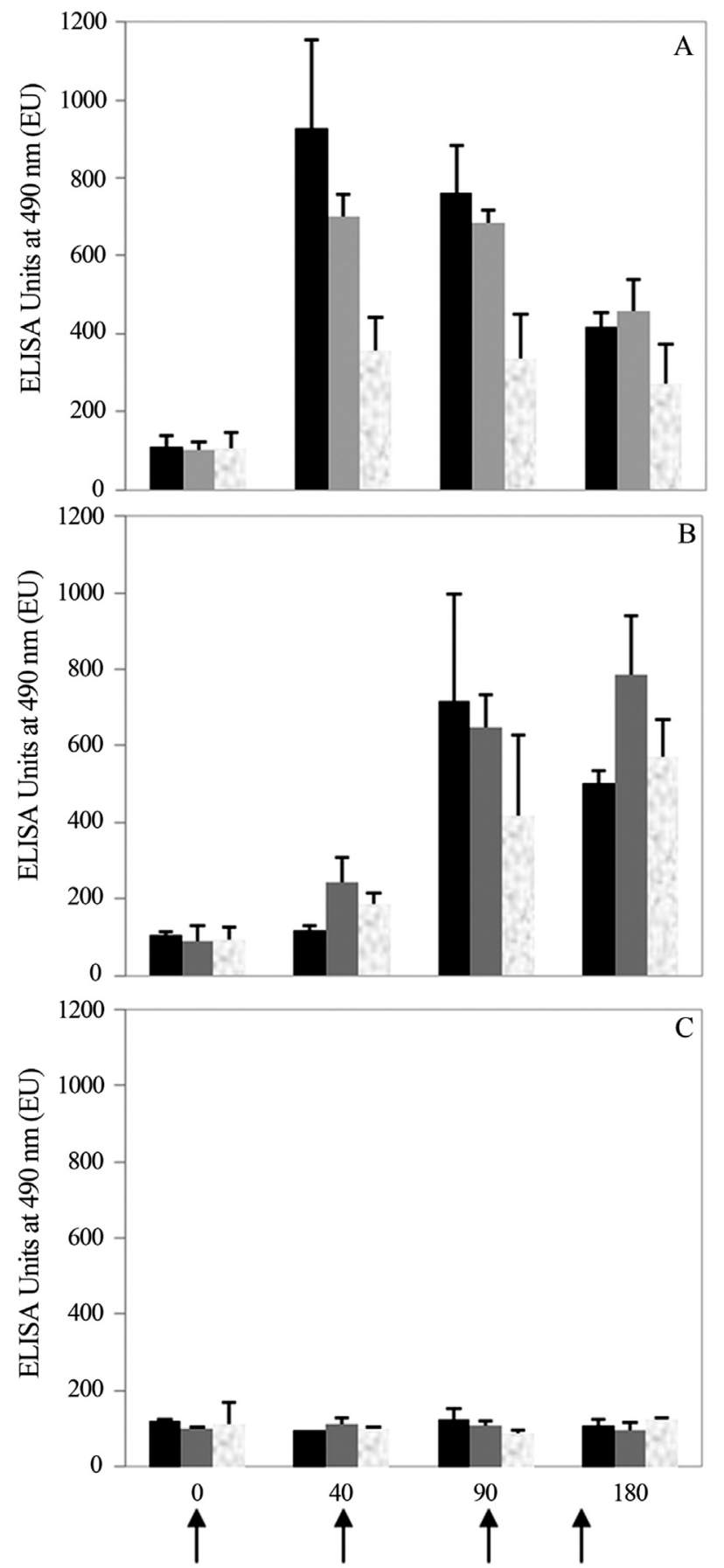

Figure 1 - Kinetics of specific antibody response from day 0 to 180 (prior to challenge) against: LAMe (black bars), Map (gray bars) and PPA (spotted bars). Mean ELISA Units (EU) \pm standard deviation of three experiments are represented for each group A) LAMv, B) Mav, C) C. EU were estimated as the mean OD value for each serum 100 / mean OD value for a pool of sera from five healthy bovines. Numbers under bars indicate days after first vaccination and arrows indicate vaccination days.

while immunization with the whole mycobacteria did interfere with this diagnostic technique, as previously reported (Muskens et al., 2002; Stabel et al., 2011).

After challenge, our results show that the levels of serum-specific antibodies significantly decreased in bovines 
of the LAMv group, as compared with the levels detected before the challenge in the same group $(\mathrm{p}<0.005$, paired $\mathrm{T}$ test) (Figure 2A). We hypothesize that the circulating antibodies induced by LAMe vaccination, priorly described as predominantly composed of IgG1 (Jolly et al., 2011), could be consumed during the intestinal replication of Map, while this isotype is the most relevant in the intestinal tract of cattle (Butler and Kehrli, 2005). Specific antibodies in control challenged bovines remained low after challenge (Figure 2A). Taking into account the relatively short experimental period and the generally delayed humoral immune response induced by Map infection, this result is not unexpected. In fact, similar results were published by other authors, detecting no antibody response during a postchallenge period of 134 (Waters et al., 2003), 150 (Munjal et al., 2007) or 210 days (Koo et al., 2004).

On days 210 and 280 (30 and 100 days postchallenge, respectively), Map was isolated from the fecal samples of the two control bovines, but not from those of challenged bovines of the LAMv group (Figure 2B). The identity of Map isolates was verified by IS $900-P C R$ and the RFLP pattern confirmed to be the same used for the challenge. To our knowledge, this paper proposes for the first time the intraruminal route for experimental infection with paratuberculosis and is the first report of challenge with a native Map strain in bovines in Argentina. It has been described that passive fecal shedding of Map occurs as early as 12 hours after oral inoculation in challenged bovines. Positive results in fecal culture from 14 days after inoculation should be considered shedding due to infection (Hines et al., 2007). In our study, the isolation of Map from feces of control challenged bovines on days 30 and 100 after the challenge demonstrated multiplication of bacteria in nonvaccinated animals. Remarkably, we were able to attempt

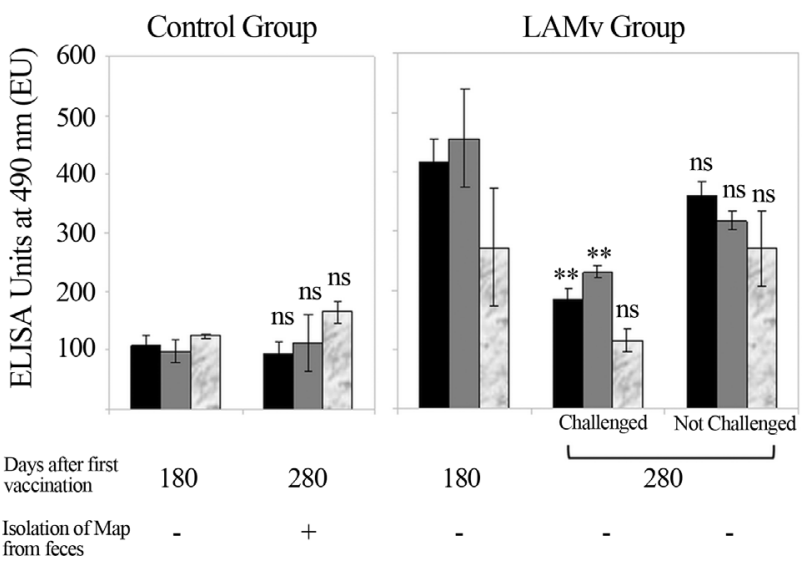

Figure 2 - Effects of Map challenge. On antibody levels. Mean ELISA Units $(E U) \pm$ standard deviation of three measurements obtained for each group are shown. Black bars represent reactivity against LAMe, gray bars against Map, and spotted bars against PPA. Text above bars indicates the group analyzed, and numbers under bars indicate days after first vaccination. ** means $\mathrm{p}<0.005$ and $\mathrm{ns}$ means no significant differences with $\mathrm{p}>0.05$, between 180 and 280 days (paired T test). On Map isolation from feces. bacterial replication in control challenged bovines, aged approximately 1 year at challenge. Generally, newborn calves are considered the most susceptible category for contracting the infection, with resistance increasing with age (Windsor and Witthington, 2010). Even so, it has been recently demonstrated that age-resistance to infection can be overcome by pressure of the infection, achieving Map infection in one- and two-year-old cattle exposed to heavily contaminated pastures (Fecteau et al., 2010).

Our results show that LAMe vaccine induces a systemic humoral immune response and affects Map excretion in challenged bovines at least until 100 days after challenge. It would have been interesting to see if different degrees of lesions develop if these bovines had been kept longer. However, this was beyond the scope of this work. Further experiments should be conducted, using more animals, the natural route of infection, and a longer postchallenge period, and including more evaluation techniques. These studies would provide useful data for the development of new strategies in paratuberculosis prevention.

\section{Acknowledgments}

We would like to thank Dr. Eloy Fernández for his valuable suggestions in the design of this experiment. This work was supported by Agencia Nacional de Promoción Científica y Técnica (BID PICT 2010-2672), Universidad de Buenos Aires (UBASeCyT 20020100100912) and Instituto Nacional de Tecnología Agropecuaria (AESA $\mathrm{N}^{\circ}$ 202831), Argentina.

\section{References}

Abbas AK, Lichtman AH (2004) Humoral immune response. Activation of B lymphocytes and production of antibodies. In: Basic Immunology. Functions and disorders of the immune system. W.B. Saunders Co., 2nd ed., 123:142.

Bastida F, Juste RA (2011) Paratuberculosis control: a review with a focus on vaccination. J Immune Based Ther Vaccines 9:8.

Butler JE, Kehrli MEJr (2005) Immunoglobulins and immunocytes in the mammary glands and its secretions. In: Mestecky, J.; Lamm, M.E.; Strober, W.; Bienenstock, J.; McGee, J.R.; Mayer, L. (eds.). Mucosal immunology. Elsevier Academic Press, 1776-1784.

Fecteau ME, Whitlock RH, Buergelt CD, Sweeney RW (2010) Exposure of young dairy cattle to Mycobacterium avium subsp. paratuberculosis (MAP) through intensive grazing of contaminated pastures in a herd positive for Johne's disease. Can Vet J 51:198-200.

Glatman-Freedman A (2006) The role of antibody-mediated immunity in defense against Mycobacterium tuberculosis: advances toward a novel vaccine strategy. Tuberculosis (Edinb). 86:191-197.

Fernández B, Gilardoni LR, Jolly A, Colavecchia SB, Paolicchi FA, Mundo SL (2012) Detection of bovine IgG isotypes in a PPA-ELISA for the diagnosis of Johnes disease in infected herds. Vet Med Int 2012:145-318. 
Hines ME $2^{\text {nd }}$, Stabel JR, Sweeney RW, Griffin F, Talaat AM, Bakker D, Benedictus G, Davis WC, de Lisle GW, Gardner IA, Juste RA, Kapur V, Koets A, McNair J, Pruitt G, Whitlock RH (2007) Experimental challenge models for Johnes disease: a review and proposed international guidelines. Vet Microbiol 122:197-222.

Jolly A, Colavecchia S, Jar A, Fernández E, Mundo S (2006) Lipoarabinoamanano (LAM) de Mycobacterium sp.: respuesta inmune inducida en terneros. In Vet 8:103-9.

Jolly A, Colavecchia S, Fernández B, Fernández E, Mundo S (2011) Antibodies induced by lipoarabinomannan in bovines: characterization and effects on the interaction between Mycobacterium avium subsp. paratuberculosis and macrophages in vitro. Vet Med Int 2011: 258-479.

Kang PB, Azad AK, Torrelles JB, Kaufman TM, Beharka A, Tibesar E, DesJardin LE, Schlesinger LS (2005) The human macrophage mannose receptor directs Mycobacterium tuberculosis lipoarabinomannan-mediated phagosome biogenesis. J Exp Med 202:987-999.

Koo HC, Park YH, Hamilton MJ, Barrington GM, Davies CJ, Kim JB, Dahl JL, Waters WR, Davis WC (2004) Analysis of the immune response to Mycobacterium avium subsp. paratuberculosis in experimentally infected calves. Infect Immun 72:6870-6883.

Moreira AR, Paolicchi F, Morsella C, Zumarraga M, Cataldi A, Bigi F, Alito A, Piet O, van Soolingen D, Romano MI (1999) Distribution of IS900 restriction fragment length polymorphism types among animal Mycobacterium avium subsp. paratuberculosis isolates from Argentina and Europe. Vet Microbiol 70:251-259.

Mundo SL, Fontanals AM, García M, Durrieu M, Alvarez E, Gentilini ER, Hajos SE (2008) Bovine IgG1 antibodies against Mycobacterium avium subsp. paratuberculosis protein p34-cx improve association of bacteria and macrophages. Vet Res 39:6.

Munjal SK, Tripathi BN, Paliwal OP, Boehmer J, Homuth M (2007) Application of different methods for the diagnosis of experimental paratuberculosis in goats. Zoonoses Public Health 54:140-146.
Muskens J, van Zijderveld F, Eger A, Bakker D (2002) Evaluation of the long-term immune response in cattle after vaccination against paratuberculosis in two Dutch dairy herds. Vet Microbiol 86:269-278.

Nielsen SS (2010) Immune-based Diagnosis of Paratuberculosis. In: Behr, M. A. and Collins, D. M. (eds.). Paratuberculosis: Organism, Disease, Control. CAB International, Oxfordshire, pp 284-293.

Nigou J, Gilleron M, Puzo G (2003) Lipoarabinomannans: from structure to biosinthesis. Biochimie. 85:153-166.

Paolicchi F, Zumárraga M, Gioffre A, Zamorano P, Morsella C, Verna A, Cataldi A, Romano M (2003) Different methods for the diagnosis of Mycobacterium avium subsp. paratuberculosis in a dairy cattle herd in Argentine. J Vet Med B Infect Dis Vet Public Health 50:20-26.

Stabel JR (1997) An improved method for cultivation of Mycobacterium paratuberculosis from bovine fecal samples and comparison to three other methods. J Vet Diagn Invest 9:375-380.

Stabel JR, Waters WR, Bannantine JP, Lyashchenko K (2011) Mediation of host immune responses after immunization of neonatal calves with a heat-killed Mycobacterium avium subsp. paratuberculosis vaccine. Clin Vaccine Immunol 18:2079-2089.

Waters WR, Miller JM, Palmer MV, Stabel JR, Jones DE, Koistinen KA, Steadham EM, Hamilton MJ, Davis WC, Bannantine JP (2003) Early induction of humoral and cellular immune responses during experimental Mycobacterium avium subsp. paratuberculosis infection of calves. Infect Immun 71:5130-5138.

Welin A, Winberg ME, Abdalla H, Sarndahal E, Rasmusson B, Stendahl O, Lerm M (2008) Incorporation of Mycobacterium tuberculosis lipoarabinomannan into macrophage membrane rafts is a prerequisite for the phagosomal maturation block. Infect Immun 76:2882-2887.

Windsor PA, Whittington RJ (2010) Evidence for age susceptibility of cattle to Johne's disease. Vet J 84:37-44.

All the content of the journal, except where otherwise noted, is licensed under a Creative Commons License CC BY-NC. 